\title{
The Frequency of the Depression Among Elderly Population and to Explore Possible Associations Between Depression Severity and Daily Accomplishments in Minia Geriatric Club
}

\author{
Yosria El-Sayed Hossein \\ Community health nursing, Faculty of nursing, Minia University, Minia, Egypt
}

Email address:

Yosria 1968@yahoo.com (Y. El-Sayed Hossien)

To cite this article:

Yosria El-Sayed Hossein. The Frequency of the Depression Among Elderly Population and to Explore Possible Associations Between Depression Severity and Daily Accomplishments in Minia Geriatric Club. American Journal of Nursing Science.

Vol. 4, No. 2, 2015, pp. 31-38. doi: 10.11648/j.ajns.20150402.12

\begin{abstract}
The aging process affects human bodies as well as human behaviors. In general, the extra years can be marked by declining health, reduced mobility that may lead to accidents, isolation, and loneliness. Some late-life problems can result in depression and anxiety include less of coping with physical health problems, caring for a spouse with dementia, and grieving the death of loved ones. The aim of the present study was to assess the frequency of the depression among elderly population and to explore possible associations between depression severity and daily accomplishments in Minia Geriatric Club. The study was conducted on 70 elderly persons (the elderly client attends the geriatric club and who agree to share in the study). The study tools are questionnaire sheet and geriatric depression scale. The questionnaires sheet the social and personal characteristics of the study sample. (Age, sex, marital status, level of education, presence of physical health problems, sensory changes, history of exposure to accident, and hobbies. While the Geriatric Depression Scale (GDS) is consisted of 30 statements, each statement is scored by one point and the total scores for are categorized into three levels as: normal 0-9; mild depression 10-19; severe depression 20-30. The study results denoted that: more than half of the study sample (55.7\%) were had mild depression and $37.1 \%$ were had sever depression. $71.4 \%$ and $65.7 \%$ of the study sample were had physical health problems and cognitive problems respectively. In addition to $47.1 \%$ of them were previously exposed to accident. There are no statistically significance differences in level of depression as regard to sex, level of dependency and level of education. But there are statistically significant differences were noted regarding level of depression and (presence of physical health problems, and sensory changes $\mathrm{P}=0.05$ ). The study concludes that depression among elderly is often associated with presence of chronic health problems with mental or social stress. Recommendation; coordination between the health team members is needed to provide holistic and optimal care for elderly clients. All forms of cognitive and supportive psychotherapy are recommended for improving depression in elders.
\end{abstract}

Keywords: Depression, Elderly, Physical Health Problem

\section{Introduction}

The aging process affects human bodies as well as human behaviors. Although some changes in health status may be unavoidable consequences of the aging process, many more are strongly influenced by health behavior, physical activity, and diet .There is a growing body of evidence that self care behaviors affect dietary choices and physical activity habits that may alter the risk of hypertension, diabetes, and coronary artery disease, and some cancers. Recent studies suggest that and physical activity can also have a marked effect on the quality of life of older adults. This may result in improvements in physical, psychological, and social functioning. However the interrelationship among optimal dietary behaviors, increased level of physical activity (Uchino\&Bert., 2006).

The world is in the midst of a demographic transition, as the proportion of people over age 60 increases and the proportion under age 15 declines. While population aging began in developed countries, this trend now encompasses developing countries as well. Currently 8 percent of the population in developing regions is over the age of 60 . As life spans increase, however, that proportion will grow to an estimated 20 percent by 2020 . Already, 62 percent of the 
world's older people live in developing regions World Health Organization. Active Aging: A Policy Framework. Geneva: WHO (2002). Available at: www.who.int/hpr/aging /Active Aging policy Frame. Pdf and (http://www.rho.org/html/older_overview.htm). Egypt is the most populous country in the Middle East and the second most populous in the African continent. Nearly $100 \%$ of the country's 78,887,007 (EST, 2006) life expectancy at birth for males is: 69.3 years, and for females is: 74.52 years (http://www.cia.gov/librarly/publications/the -world-factbook/index.html.)

Table 1. Population percentage by Age Group as of January 2006

\begin{tabular}{lllllll}
\hline \multirow{2}{*}{ Age } & Males & & Females & & \multicolumn{2}{l}{ Total } \\
\cline { 2 - 7 } & Number & $\mathbf{\%}$ & Number & $\mathbf{\%}$ & Number & $\%$ \\
\hline Over 60 years & 2126162 & 5.8 & 11197633000 & 5.7 & 4102492 & 5.8 \\
\hline
\end{tabular}

Report of the central Authority for public Mobilization and Statistics (CAPMAS), January, 2005.

The growth of the population ages 65 and older in has steadily increased since the beginning of the twentieth century. In 1900, approximately $4 \%$ of the population was over age 65 ; today, older alder account for nearly $13 \%$ of the population. In the year 2030, the percentage of individuals over age 65 in projected to be about $25 \%$. In the year 2000 , there were 50,454 centenarians (individuals 100 years and older), and the number is expected to increase to about 500,000 in 2030 . Reflecting the general U.S population, the older population is more racially diverse than in the past. The effect this demographic shift has had on nursing practice in all settings is considerable. Estimates are that two thirds of a nurse's career today is spent working with older adults. Because most health care for these clients is delivered outside the acute care setting (Simon, Fletcher, and Francis, 1998).

Most older adults live in a noninstitutional community setting, and a majority (67\%) of them live with someone. About $4.5 \%$ live in a nursing home, a likelihood that increases significantly as one ages. More than half of people over age 65 report having difficulty in carrying out basic activities of daily living (ADLs, such as bathing, dressing, eating) and instrumental activities of daily living (ADLs, such as preparing meals, taking medication, managing money), with a disproportionate share of individuals with disability in the older age groups. In 1997, more than half $(54.5 \%)$ of the older population reported having at least on disability. The percentages with disabilities and a need for assistance with ADLs and IADLs increase sharply with age (Westley\& Fletcher, 2002).

We live in an aging society. Not only is 1 in every 8 older than 65 years, but a person aged 65 can expect to live an average of 18 more years. People aged 85 years and over are the fastest - growing group, and the proportion of these "Oldest old" is expected to triple between now and year 2030. Continued good health of the elderly population is a major challenge to public health. Increased longevity with an increase in multiple chronic conditions that sometimes translate into functional disability and need for assistance. The extra years can be marked by declining health, reduced mobility, depression, isolation, and loneliness. Health and functioning of older adults are influenced by many factors other than biological senescence. Demographic, social and environmental factors including physical activity and dietary habits play a major role. Fortunately, many of these societal factors are amenable to public health interventions and programs. More than any other age group, older adults are seeking health information and are willing to make behavioral changes to maintain their health and independence into advanced old age (Journals of Gerontology Series, 2001).

Older adults enjoy good mental health. However, it is anticipated that the number of older adults with mental and behavioral health problem Will almost quadruple, from 4 million in 1970 to 15 million in 2030. Mental health disorders, including anxiety and depression, adversely affect physical health and ability to function, especially in older adults. Some late-life problems that can result in depression and anxiety include coping with physical health problems, caring for a spouse with dementia a physical disability, grieving the death of loved ones, and managing conflict with family members. Addressing these problems and treating often overlooked mental health conditions results in decreased emotional suffering, improved physical health, lessened disability, and a better quality of life for older adults and their families. Increasing access to mental health services for older adults will reduce health care expenditures by lowering the frequency of primary care visits, medical procedures, and medication use.

Increase coordination of mental and physical health care. Because of the often-complex interplay of physical and mental health problems in older adults, interdisciplinary care is needed to provide optimal care.

Depression in older adults is a very treatable disorder. However, symptoms of depression in older adults are often overlooked because they are inaccurately assumed to be a normal part of aging or may coincide with medical illness or life events that commonly occur as people age. Psychologists successfully identify and treat both major depressive disorder and subclinical forms of depression with psychotherapy (Tower et al., 2000).

In about $30 \%-50 \%$ of cases, depression in older adults is the continuation of a problem that began earlier in life. Major depression is a disease that often comes back in both younger and older adults. Without treatment, up to one third of depressed individuals stay depressed for a long time, and another third recover only partially, leaving them with lingering disability and on-going problems. People who suffer their first episode of depression in later life take longer to recover. Depression that begins in later life is often associated with chronic medical illness, disability, or mental or social stress. However, usually no cause can be identified for any particular episode of depression in later life.

The diagnosis of major depression in older adults is often complicated by physical illness. Many older adults have 
illnesses such as cancer or heart disease that, in practice. Understandably, make them feel sad, lonely, or depressed. People with serious medical illness may even be preoccupied with thoughts about death or feel worthless because of disability associated with their illness. However, these feelings are related to their illness and are not truly major depression (Blazer, D. 2003).

Depression in elderly people is a widespread and serious public health concern," according to the National Institute of Mental Health. It has been estimated that $15 \%$ of older Americans experience depression at some point in their golden years. In nursing homes, around $20 \%$ of the residents are depressed, especially those living with a serious medical condition, like cancer or heart disease. Depression goes under-diagnosed and under-treated in older Americans and this can seriously affect the worth of their life and their overall functioning. If ignored long enough, or, if the severity increases, depression could lead to suicide. In fact, America's older population is responsible for $25 \%$ of completed suicides. (Buckley, J. B, 2009).

Depression among senior citizens is a more common problem then people might think. Statistics show that approximately 6 million Americans age 65 and older suffer from depression. Among them, only 10 percent receive proper treatment. Unfortunately, late-life depression is usually confused with the effects of the multiple illnesses associated with this age and the medication used for their treatment, or it is considered normal among elders. However, it must be emphasized that depression is NOT a part of the normal aging process. Depression substantially increases the risk for death in those that suffer from medical conditions or physical illnesses. It can increase the impairment resulted from the medical problem by stopping the improvement progress and can interfere with person's ability to follow a recovery plan and the necessary treatment (Morrow, A. Depression, Conditions \& Diseases: Psychological \& Mental Health, 2009).

Several studies in the United States, Germany, and Japan have revealed a direct relationship between the amount of physical activity in one's life and the incidence of depression (Landrevillep. etal. 2001). That is, the greater the amount of physical activity, the lower the risk of depression and its symptoms. Although some physicians and psychological clinics now prescribe exercise for depressed patients, an increase in physical activity or fitness in normal individuals will not necessarily change their depressive state. But those individuals who engage in high levels of physical activity also have a greater feeling of well-being and improved self-image. This condition results from moderate but regular exercise behaviors rather than intense, lengthy bouts of exercise (Emma Funnell, 2008).

\section{Aim of the Study}

To assess The Frequency of the Depression Among Elderly Population and to Explore Possible Associations Between Depression Severity and Daily Accomplishments in Minia Geriatric Club.

\section{Subjects and Method}

\subsection{Research Design}

A cross descriptive study was utilized in this study

\subsection{Subject}

The study was conducted on 70 elderly persons who obtained the following criteria:

1. Age over 60 years.

2. Attends the geriatric club.

3. Agree to share in the study.

\subsection{Method of Data Collection}

Prior to data collection the necessary approval was secured from the director of Minia Geriatric club. A pilot study was done on ten elderly persons form the geriatric club, to test the questionnaire for its validity, reliability and clarity. The purpose of the study was explained to elderly person and take the consent to participated in the research, the time required to complete the questionnaire was about (20-25) minutes.

Data was collected though structured interview (from December 2008 to February 2009 researcher went to the geriatric club on Monday and Wednesday). Each subject interviewed individually at geriatric club hall.

\subsection{Tools of the Study}

"The frequency of depression was screened using the GDS that has been widely used in Arabia Nation/or not....." and continue with the description of GDS.... Demographic data are also assessed using a structured questionnaire (tool) including social and personal characteristics of the study sample (age , sex, marital ........

It consist of two parts, the first part was related to social and personal characteristics of the study sample (age, sex, marital status, level of education, presence of physical health problems, sensory changes, cognitive changes, history of exposure to accident, activity of daily living, and social hobbies).

The second part was Geriatric depression Scale (GDS) it consisted of 30 items the total score for the scale is 30 , This tool was translated to Arabic languish by the researcher and revised by three expert in nursing field. Each statement is scored by one point as the following:

One point for each of statement answers:

1. no 6. yes 11 . yes 16 . yes 21 . no 26 . yes

2. yes 7. no 12. yes 17 . yes 22. yes 27. no

3 . yes 8 . yes 13 . yes 18 . yes 23 . yes 28 . yes

4. yes 9. no 14. yes 19. no 24. yes 29. no

5. no 10 . yes 15 . no 20 . yes 25 . yes 30 . no

The total scores are categorized into three levels as: normal 0-9; mild depression 10-19; severe depression 20-30 (http:// www.stanford.edu/Yesavage/GDS.html

\subsection{Statistical Analysis}

All data of the study were fed into an IBM-Compatible personal computer. SPSS-12 (statistical software) was used 
for statistical analysis. Comparison between groups of variables was done by Chi-square (for non-parametric data). $\mathrm{P}$ value was considered significant when $\mathrm{P}<0.05$.

\section{Results}

As shown the table 2 show that, the majority of the study sample $(77.1 \%)$ were male, more than half $(54.3 \%)$ were between 65 and less than 75 years old, (32.9\%) of them were single and less than half $(41.4 \%)$ were elementary. The study results donated that $71.4 \%$ and $65.7 \%$ of the study sample were had physical health problems and cognitive problems respectively. In addition to nearly half $(47.1 \%)$ of them were previously exposed to accident.

Table 2. Distribution of the socio-demographic characteristics of the study sample $(n=70)$.

\begin{tabular}{lcc}
\hline Demographic & No & \% \\
\hline Age: & 20 & 28.6 \\
1- $60<65$ year & 38 & 54.3 \\
2- $65<75$ year & 12 & 18.1 \\
3- $75+$ & & \\
Mean \pm SD $(68.2 \pm 6.8)$ & & \\
Sex: & 54 & 77.1 \\
1- Male & 16 & 22.9 \\
2- Female & & \\
Marital status: & 21 & 30.0 \\
1- Married & 23 & 32.9 \\
2- Single & 12 & 17.1 \\
3- Widow & 14 & 20.0 \\
4- Divorced & & \\
Level of education: & 10 & 14.3 \\
1- Illiterate & 29 & 41.4 \\
2- Elementary & 26 & 37.1 \\
3- Secondary & 5 & 7.1 \\
4- University & & \\
\hline
\end{tabular}

It can be noted from table 3 that about two thirds of the study sample $(62.9 \%)$ were had sensory changes and nearly half of them $(47.1 \%)$ were exposed to fall or accident previously. regarding activity of daily living $38.6 \%$ of the study sample were dependent while $42.9 \%$ were independent. Also $40 \%$ of elderly person had in continuity with their social hobbies.

Table 4 indicated that more than half of the sample (55.7\%) had mild depression while more than one third of them $(37.1 \%)$ had sever depression.

Table 5 illustrated that, about one third of the study sample $(34.4 \%)$ who had physical health problems were complain sever depression and $(30.0 \%)$ of them had mild depression. There are statistically significant difference between level of depression regarding to presence of physical health problem $(\mathrm{P}$ - Value $=0.05)$.

Table 6 showed that, (41.4\%) the study sample who had sensory changes were complain mild depression also (17.2\%) of them had sever depression. There are statistically significant difference between level of depression regarding to sensory changes $(\mathrm{P}-$ Value $=0.05)$. It can be noted from.
Table 7 that, (41.4\%) of the study sample who had no social hobbies were suffer from mild depression while that was statistically significant $(\mathrm{P}-$ Value $=0.05)$.

From table 8 it can be noted that, there are no statistically significance differences in level of depression as regard to marital status.

Statistical analysis revealed also that, there are no statistically significance differences were founded between level of depression and level of dependency and level of education).

Table 9 Concerning Geriatric depression Scale (GDS) it can be observed that, the majority of the study sample their response was (No) for the following items (Are you basically satisfied with your life, Are you hopeful about the future, Do you frequently worry about the future, Do you feel happy most of the time, Do you frequently worry about the future, Do you find life very exciting).

Table 3. Distribution of the studied sample according to physical health status and activity of daily living $(n=70)$.

\begin{tabular}{lll}
\hline Items & No.= (70) & \% \\
\hline I- Ability to walk & & \\
Walk alone & 48 & 68.6 \\
Need a help in walking & 22 & 31.4 \\
II- Nutritional Habit & & \\
Follow a specific nutrition & 26 & 37.1 \\
Normal Nutrition & 44 & 62.9 \\
III- Sensory Changes & & \\
Yes & 44 & 62.9 \\
No & 26 & 37.1 \\
IV-previous exposure to fall & & \\
Yes & 33 & 47.1 \\
No & 37 & 52.9 \\
V- Activity of daily living & & \\
Dependent & 27 & 38.6 \\
Need a part of assistant & 13 & 18.6 \\
Independent & 30 & 42.9 \\
VI- Social hobbies activity & & 40.0 \\
Yes & 28 & 60.0 \\
No & 42 & \\
\hline
\end{tabular}

Table 4. Distribution of level of depression among the study sample $(n=70)$.

\begin{tabular}{lll}
\hline Level of depression & No. & \% \\
\hline Normal & 5 & 7.1 \\
Mild & 39 & 55.7 \\
Sever & 26 & 37.1 \\
Total & 70 & $100.0 \%$ \\
\hline
\end{tabular}

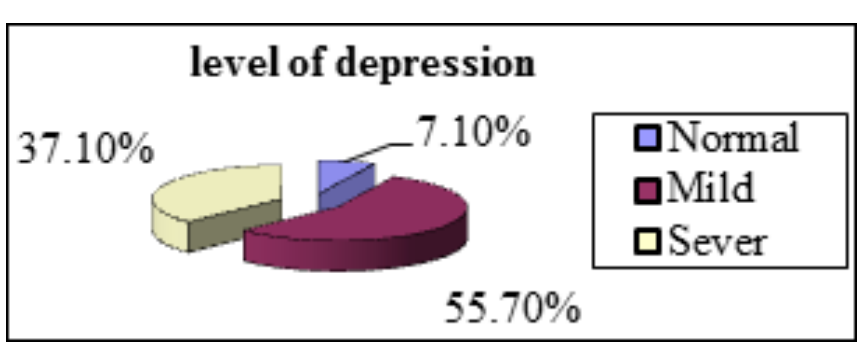


Table 5. Comparison between level of depression and presence of health problems $(n=70)$.

\begin{tabular}{lllll}
\hline \multirow{2}{*}{ Level of depression } & \multicolumn{4}{l}{ Presence of physical health problems } \\
\cline { 2 - 5 } & \multicolumn{3}{l}{ Yes } & No \\
\cline { 2 - 5 } & No. & \% & N0. & \% \\
\hline Normal & 5 & 7.1 & 0 & 0.0 \\
Mild & 25 & 30.0 & 15 & 21.4 \\
Sever & 21 & 34.4 & 5 & 7.1 \\
Total & 50 & 71.5 & 20 & 28.5 \\
\hline
\end{tabular}

* Chi-Square (4.98)

P-Value (0.05)

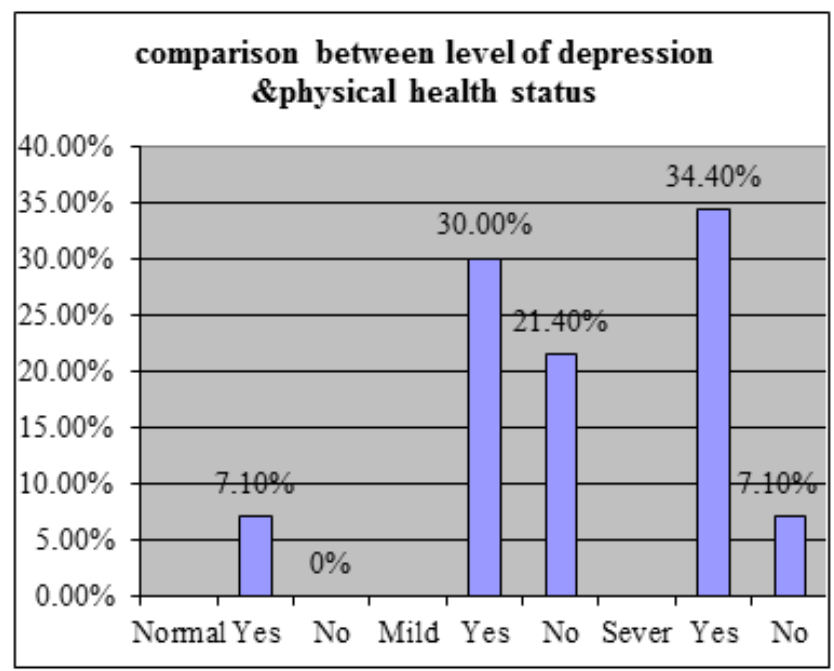

Table 6. Comparison between level of depression and sensory changes $(n=$ 70).

\begin{tabular}{lllll}
\hline \multirow{2}{*}{ Level of depression } & \multicolumn{4}{l}{ Presence of sensory changes } \\
\cline { 2 - 5 } & \multicolumn{3}{l}{ Yes } & No \\
\cline { 2 - 5 } & No. & \% & N0. & \% \\
\hline Normal & 3 & 4.3 & 2 & 2.9 \\
Mild & 29 & 41.4 & 10 & 14.3 \\
Sever & 12 & 17.2 & 14 & 20.0 \\
Total & 44 & 62.9 & 26 & 37.1 \\
\hline
\end{tabular}

Chi-Square (5.33), P-Value (0.05)

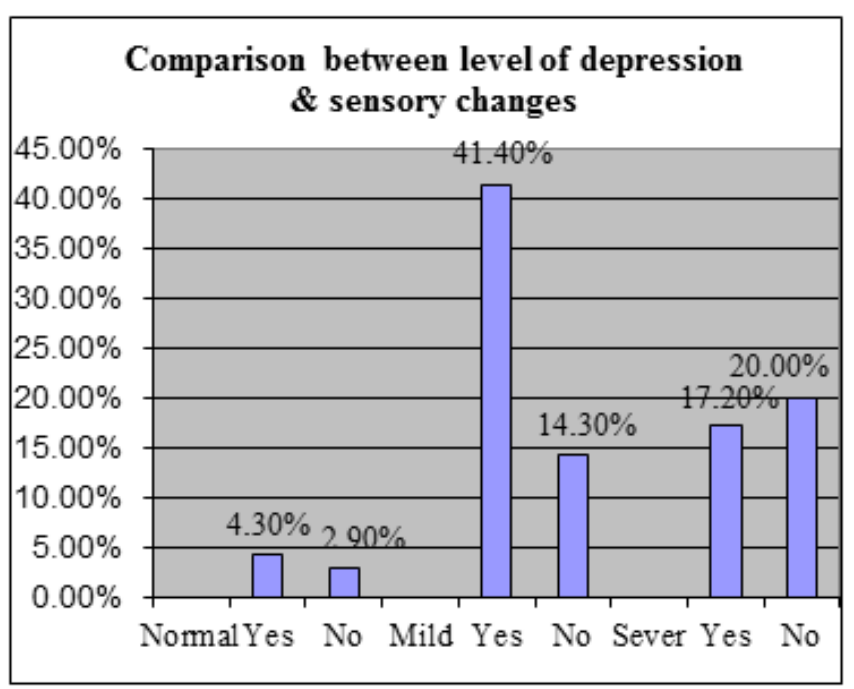

Table 7. Comparison between level of depression and social hobbies activities $(n=70)$.

\begin{tabular}{lllll}
\hline \multirow{2}{*}{ Level of depression } & \multicolumn{3}{l}{ Continuity of hobbies } \\
\cline { 2 - 5 } & \multicolumn{2}{l}{ Yes } & \multicolumn{3}{l}{ No } & \\
\cline { 2 - 5 } & No. & \% & N0. & \% \\
\hline Normal & 2 & 2.9 & 3 & 4.3 \\
Mild & 10 & 14.3 & 29 & 41.4 \\
Sever & 16 & 22.8 & 10 & 14.3 \\
Total & 28 & 40.0 & 42 & 60.0 \\
\hline
\end{tabular}

* Chi-Square (8.37)

P-Value $(0.05)$

Table 8. Correlation between Marital status and Level of Depression.

\begin{tabular}{llllll}
\hline \multirow{2}{*}{$\begin{array}{l}\text { Level of } \\
\text { Depression }\end{array}$} & \multicolumn{3}{l}{ Marital status } & \multirow{2}{*}{ Total } \\
\cline { 2 - 5 } & Married & Single & Widow & Divorced & \\
\hline Normal & 2 & 2 & 1 & 0 & 5 \\
Mild & 14 & 13 & 4 & 8 & 39 \\
Sever & 5 & 8 & 7 & 6 & 26 \\
Total & 21 & 23 & 12 & 14 & 70 \\
\hline
\end{tabular}

Chi-Square. (5.42) P value (0.491)

Table 9. Distribution of depression scale variables $(\mathrm{No}=70)$.

\begin{tabular}{|c|c|c|c|c|c|}
\hline & \multirow{2}{*}{ Depression scale variables } & \multicolumn{2}{|l|}{ Yes } & \multicolumn{2}{|l|}{ No } \\
\hline & & No. & $\%$ & No. & $\%$ \\
\hline $1-$ & Are you basically satisfied with your life & 27 & 38.6 & 43 & 61.4 \\
\hline $2-$ & Dropped many of your activities & 53 & 76.7 & 17 & 24.3 \\
\hline $3-$ & Do you feel that your life empty & 50 & 71.4 & 20 & 28.6 \\
\hline 4- & Do you often get bored & 49 & 70.0 & 21 & 30.0 \\
\hline $5-$ & Are you hopeful about the future & 21 & 30.0 & 49 & 70.0 \\
\hline 6 & Are you bothered by thought & 43 & 61.4 & 27 & 38.6 \\
\hline 7 & Are you in good spirit most time & 56 & 80.0 & 14 & 20.0 \\
\hline 8 & $\begin{array}{l}\text { Are you afraid that something bad is } \\
\text { going to happen to you }\end{array}$ & 18 & 25.7 & 52 & 71.3 \\
\hline 9 & Do you feel happy most of the time & 32 & 45.7 & 38 & 54.3 \\
\hline 10 & Do you often feel helpless & 50 & 71.4 & 20 & 28.6 \\
\hline 11 & Do you rest less \& fidgety & 50 & 71.4 & 20 & 28.6 \\
\hline 12 & Do you prefer to stay at home & 40 & 57.1 & 30 & 42.9 \\
\hline 13 & $\begin{array}{l}\text { Do you frequently worry about the } \\
\text { future }\end{array}$ & 20 & 28.6 & 50 & 71.4 \\
\hline 14 & Do you feel you have problem & 17 & 24.3 & 53 & 75.7 \\
\hline 15 & Do you think it is wonderful & 29 & 41.4 & 41 & 28.6 \\
\hline 16 & Do you often feel downhearted & 51 & 72.9 & 19 & 27.1 \\
\hline 17 & Do you feel pretty worthless & 46 & 65.7 & 24 & 34.3 \\
\hline 18 & Do you worry a lot about the past & 24 & 34.3 & 46 & 65.7 \\
\hline 19 & Do you find life very exciting & 10 & 14.3 & 60 & 85.7 \\
\hline 20 & Get started on new projects & 26 & 37.1 & 44 & 62.8 \\
\hline 21 & Do you feel full of energy & 22 & 31.4 & 48 & 68.6 \\
\hline 22 & $\begin{array}{l}\text { Do you feel that your situation is } \\
\text { hopeless }\end{array}$ & 50 & 71.4 & 20 & 28.6 \\
\hline 23 & Most people are better off than you & 56 & 80.0 & 14 & 20.0 \\
\hline 24 & Upset over little things & 57 & 81.4 & 13 & 18.6 \\
\hline 25 & Do you frequently feel like crying & 48 & 68.6 & 22 & 31.4 \\
\hline 26 & Do you have trouble concentrating & 29 & 41.4 & 41 & 58.6 \\
\hline 27 & Do you enjoy getting up in the morning & 36 & 51.4 & 34 & 48.6 \\
\hline 28 & Do you prefer social gathering & 42 & 60.0 & 28 & 40.0 \\
\hline 29 & Is it easy for you to make decisions & 34 & 48.6 & 36 & 51.4 \\
\hline 30 & Is your mind as clean as it used to be & 33 & 47.1 & 37 & 52.9 \\
\hline
\end{tabular}

\section{Discussion}

The main finding of the present study was that the frequency of depression in our sample was increased as age increased and/or greater than other European or Asian or 
American countries suggesting that... assess the frequency of the depression among elderly population and to explore possible associations between depression severity and daily accomplishments.

World Health Organization, 2007 predicted that by the year 2030 , depression will become the second leading cause of disability worldwide. (WHO, 2007).

Depression in the elderly is very common and may be difficult to diagnose. Because of its varied presentation and its frequent association with physical illness it will be encountered increasingly by all physicians as the elderly populations expands. Depression through treatable, is often not treated and suicide rates are high among depressed elderly persons. Diagnostic difficulties lie in distinguishing depression from organic brain syndromes, from so called masked depression and from normal grief reactions. Pharmacologic treatment is effective but care must be taken to recognize side effects and to use adequate doses. Psychological approaches should focus on reducing felling of haplessness and feeling self-esteem. The importance of the losses borne by elderly persons in the pathogenesis of depression continuous to be theoretical and practical interest (Donald w, 2001).

\subsection{Socio-Demographic Characteristics of the Study Sample}

Regarding to elderly age more than half (54.3\%) were between (65and less than 75 years old). The majority of the study sample $(77.1 \%)$ were male $(32.9 \%)$ of them were single and less than half $(41.4 \%)$ were elementary education. The result of the present study is agreement with (Donald, 2001) who mentioned that, prevalence rates are much higher in depression, it accounts for most of the mental disorders occurring late in life. Depressions in the elderly are important public health problems, and will become even more important as the elderly population expands. Also agree with (Hannah E.,2009 ) who reported that, the symptoms of depression in elderly remains stable across the age categories (65-74 and 75-79) there after declining with elders, transition to the age categories (80-48 and 85 or more. Also agreement with (Dean, 1999) who told that, the older suffered from depressive symptoms when associated with increased age .Also (Donald $\mathrm{w}, 2002$ ) mentioned the highest rates of depressive symptoms are found in those over 65 years of age, thirty percent of people over age 65 suffer from moderate to severe psychiatric disorder. Fifty percent of depressed geriatric patients experience their first depressive episode after age 60 .

There is significant differences were seen by sex, age , marital status regarding to depression symptoms and female elders in the present study reported higher levels of depression compared to males.

\subsection{Physical Health Status and Activity Daily Livening}

From table 3 that about two thirds of the study sample $(62.9 \%)$ was had sensory changes and nearly half of them (47.1\%) were exposed to fall or accident previously. regarding activity of daily living $38.6 \%$ of the study sample were dependent while $42.9 \%$ were independent. Also $40 \%$ of elderly person had in continuity with their social hobbies. This results is agreement with (Spitze G., 2000) who mentioned depression in the elderly followed by deterioration in health activities of daily living, poor current health, poor social support, low current activity levels and predict cognitive decline. Also agreement with (StephenC. 2003) who told depression in elderly impaired functional as activities of daily living such as bathing, showering, dressing, eating, walking and preparing meals.

\subsection{Level of Depression among the Study Sample}

Table 4 indicated that more than half of the sample (55.7\%) had mild depression while more than one third of them $(37.1 \%)$ had severe depression. This agreement with (Mccusker, J. et al, 2007 ) estimated that $46 \%$ of their study had major depression, $18 \%$ had minor depression, while $36 \%$ had no depression. Also agree with (Donald w., 2001) who estimated that, mild depression which is sometimes also early depression, is very common in the elderly. Also (Jongenelies et al, 2004) found prevalence rates of depression ranging from $6 \%$ to $26 \%$ for major depression, from $11 \%$ to $50 \%$ for minor depression and from $30 \%$ to $48 \%$ for depressive symptoms, as measured by symptoms rating scales.

\subsection{Level of Depression and Presence of Health Problem}

The present study indicated that there are a positive relation between depression and chronic health disease this agree with (Redwood, 2009) who mention that, there is a clear link between chronic disease and depression. Also (Donald w., 2001) estimated that, there is a close relation between physical illness and depression in the elderly (30\% to $50 \%$ of elderly patients with physical disease also have an affective disorder. According to the National Institute of Mental Health, depression in elderly people is a widespread and serious public health. It has been estimated that $15 \%$ of older Americans experience depression at some point in their golden years. In nursing homes, around $20 \%$ of the residents are depressed, especially those living with a serious medical condition, like cancer or heart disease. Also physical illness can directly cause the symptoms of depression by causing chronic pain or fear of pain, fear of disability, dependence or immobility, or a loss of self- esteem. Chronic or serious illness is the most common cause of depression in the elderly. But even when someone is struggling with a chronic illness such as arthritis, it is not natural to be depressed. Depression is defined as an illness if it lasts two weeks or more and if it affects one's ability to lead a normal life (Buckley, 2009).

\subsection{Level of Depression and Sensory Changes}

The present study indicated that there is a positive relation between.

Level of depression regarding to sensory changes This agree with (Kathleen, 2003) who mentioned that health problem like failing vision, sensory loss and chronic disease 
like diabetes do raise an elderly person's risk for mental health problems. Other research suggests that poor vision can contribute to depression. Also agree with (Jongenelis et al, 2004) who found positive associations between visual and hearing impairments in relation to depression.

\subsection{Level of Depression and Social Hobbies Activities}

The present study indicated that there is a positive relation between no social hobbies was suffering from mild depression. This agreement with (Buckley, 2009) who revealed that elderly needs exercise, walk daily for better circulation and mental, gardening, hobbies, recreation and sports. Also depression loss of interest or pleasure in daily living.

\subsection{Marital Status and Level of Depression}

From table 8 it can be noted that, there are no statistically significance differences in level of depression as regard to marital status.

Statistical analysis revealed also that, there are no statistically significance differences were founded between level of depression and (level of dependency and level of education). This finding agree with (Chong, 2001) who mentioned a high of depressive disorders was found among widow with low educational level but disagree with (Stephen,2003) who reported there is a significant differences were seen by sex, age, marital status and level of education.

Concerning Geriatric depression Scale (GDS) it can be observed that, the majority of the study sample their response was (No) for the following items (Are you basically satisfied with your life, Are you hopeful about the future, Do you frequently worry about the future, Do you feel happy most of the time, Do you frequently worry about the future, Do you find life very exciting). This may be attributed to the fact about the majority of the study sample $(55.7 \% \& 37.1 \%)$ had mild and severe depression, this funding is agreement with (Rapp et al, 1998) who indicated that prevalence rates for mild depression high in elderly population and the geriatric depression scale had the best reliability and validity and were the most efficient.

\section{Conclusion}

The study concludes that depression a major health problem among elderly is often associated with presence of chronic health problems, disability, with mental or social stress and sensory changes.

\section{Recommendation}

1-Recommendation; coordination between the health team members is needed to provide holistic and optimal care for elderly clients.

2- All forms of cognitive and supportive psychotherapy are recommended for improving depression in elders.

3- Reducing the level of depression may be helpful to improve the quality of life for elders through health care - givers (either formal or informal).

4- Health programs and mass media should provide more social programs for elderly to interact more closely with their families and friends to increase their social activity levels and enabling elders to reflect there feeling therefore reducing occurrence of depression

\section{References}

[1] Redwood, H. (2009). Elderly and depression: How to understand Depression in the elderly $1 / 4$,

[2] Jongenelies K., Pot A.M., \&EissesA.T.,( 2004). Prevalence and risk indicators of depression in elderly nursing home patients: the AGED study. Journal of Affective Disorders (JRC) Issue: $12,2005$.

[3] Buckley, J. B. (2009). Recognizing Depression in Elders. Today's caregiver,

[4] WHO (2002). Available at:www.who.int/hpr/aging /Active Aging policy $\quad$ Frame. Pdf (http://www.rho.org/html/older_overview.htm). http://www.cia.gov/loibrary/publications/the -world -fact book/index html.

[5] Cynthia j\& Kathleen R.,Health care of older adult ,chapter 29,P700- 702, 2007.

[6] Report of the central Authority for public Mobilization and Statistics (CAPMAS), January1, 2005.

[7] Tower R.B., kasl S., (2000) Depressive symptoms across older spouse: Psychology and aging. vol.11, n4, pp. 683-697.

[8] Blazer, D. (2003). Depression in Late Life: review and Commentary. The Journals of Gerontology, Washington, 58A, $3,249$.

[9] Spitz, G., \& Ward, R. (2000) .Gender, marriage, and expectations for personal care. Research on aging, 22,451.

[10] Uchino, Bert, N. (2006). Group Therapy for Depressed Elderly Women. International Journal of Group Psychotherapy, New York, 54, 3, 295.

[11] Dean \&Bruce B. (1999). The Association of age and depression among the elderly: An epidemiological exploration. Vol.46 no.1, pp. 210- 215 .

[12] Journals of Gerontology Series A. (2001): Biological Sciences and Medical Sciences.

[13] Landreville, P., Landry, J., Baillargeon, L., Guerrette, A., \& MatteauE., (2001). older adults Acceptance of Psychological and Pharmacological Treatments for Depression the Journals of Gerontology, Washington, 56B, 5, 285-292.

[14] Hannah, E. Elders with Diabetes (2009): Implications for Depression Screening, Boise State University Theses and Dissertations. Paper 16.

[15] Donald WM.SalzmanC, SchatzbergAF. (2002). Depression in the elderly. Fuqua Centerfor Late - Life depression, Emory University, Atlanta,USA.Pub Med,p. 21-22.

[16] StephenC., usha S.\&James T.,( 2003). Diagnosis and treatment of depression in the elderly. Pub Med journal page 1718-1728. 
[17] Chong MY, Tsang HY, Chen CS, \& TangTC. (2001). Community study of depression in old age in Taiwan: prevalence, life events and socio - demographic. Asian Nursing Research, 178: p. 29-35.

[18] McCusker, J. Latimer, E. Cole, M. (2007). Major depression among medically ill elders contributes to sustained poor mental health in their informal caregivers, vol.3, No. 3, p. 157-173. (http:// www.stanford.edu/Yesavage/GDS.html).

[19] Rapp, Stephen R., Sharon A., \& Clinton E. (1998). Detecting depression in elderly medical inpatients, vol. 56(4), Aug 1998, P. 509-513.

[20] Emma Funnel, (2008). Depression in the elderly. Oxford Journals Medicine, Innov Ait, vol.3 No. 4, p. 199- 208.

[21] De Leo, D., Hickey, P., Meneghal, G., \& Cantor, C. (1999). Blindness, Fear of Sight, and Suicide. Psychosomatics, Washington, 40, 4, 339-445.

[22] Dixon, C., Michael, R., \& Rollins, C. (2003). Contemporary Issues Facing Aging Americans: Implications for Rehabilitation and Mental Health Counseling. Journal of Rehabilitation, Alexandria, 69, 2, 5.

[23] Huisani, B., Cummings, S., Kilbourne, B., \& Roback, H. (2004). Group Therapy for Depressed Elderly Women. International Journal of Group Psychotherapy, New York, 54, 3, 295.

[24] Lee, G. R., Netzer, J. K., \& Coward, R. T. (1995). Depression Among Older Parents: The Role of Intergenerational Exchange. Journal of Marriage and the Family, 57, 3, 823.
[25] Lenze, E., Rogers, J., Martire, L., Mulsant, B., et al. (2001). The Association of Late-Life Depression and Anxiety with Physical Disability. The American Journal of Geriatric Psychiatry, Washington, 9, 2, 113-136.

[26] Morris, V. (2004). How to Care for Aging Parents, New Edition. New York: Workman Publishing, Pages 280-289.

[27] Sandberg, J. \& Harper, J. (1999) Depression in Mature Marriages: Impact and Implications for Marital Therapy. Journal of Marital and Family Therapy, 25, 3, 393-407.

[28] Sherrell, K., Buckwalter, K., \& Morhardt, D. (2001). Negotiating Family Relationships: Dementia Care as a Midlife Developmental Task. Families in Society, 82, 4, 383-393.

[29] Styron, W. (1990). Darkness Visible: A Memoir of Madness. New York: Random House, pages 7 and 33.

[30] Weeks, S. K., McGann, P. E., Michaels, T. K., \& Penninx, B. W. (2003). Comparing Various Short-Form Geriatric Depression Scales Leads to the GDS-5/15. Journal of Nursing Scholarship, Indianapolis, Second Quarter, 35, 2, 133.

[31] Yeates, C. (2001). Suicide in Later Life: A Review and Recommendations for Prevention. Suicide and Life Threatening Behavior, New York, 31, 32-48.

[32] Redwood, H.( 2009) .Elderly and depression: How to understand Depression in the elderly $1 / 4$

[33] Buckley, J. B. (2009): Recognizing Depression in Elders. Today's caregiver 